\title{
Molecular Insights of Immune Responses Variability in COVID-19 Patients: A Review
}

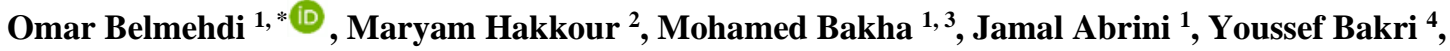 \\ Abdelhakim Bouyahya ${ }^{4}$ \\ 1 Biotechnology and Applied Microbiology Team, Department of Biology, Faculty of Science, Abdelmalek Essaadi \\ University, BP2121,93002Tetouan, Morocco \\ 2 Laboratory of Zoology and General Biology, Faculty of Sciences, Mohammed V University in Rabat, Rabat, Morocco \\ 3 Institut National de la Recherche Agronomique, CRRA-Rabat, PB6570, 10101 Rabat, Morocco \\ 4 Laboratory of Human Pathologies Biology, Department of Biology, Faculty of Sciences, and Genomic Center of Human \\ Pathologies, Faculty of Medicine and Pharmacy, Mohammed V University in Rabat, Morocco \\ * Correspondence: belmehdiomar@hotmail.fr;
}

Received: 18.11.2020; Revised: 7.01.2021; Accepted: 10.01.2021; Published: 19.01.2021

\begin{abstract}
Currently, a novel coronavirus disease 2019 (COVID-19) caused by SARS-CoV-2 has emerged worldwide. This chronic viral infection causes an acute respiratory distress syndrome (ARDS) which its pathophysiology is not yet well elucidated. However, ARDS has shown that ARDS causes diffuse alveolar damages induced by an excessive inflammatory response and a lack of antiinflammatory response to the virus. Furthermore, these pathophysiological characteristics are associated with multiorgan failure and can increase the mortality rate. The difference in immune system response against COVID-19 is not well known. However, variability in innate immune system receptors between patients infected with SARS-CoV-2 as a function of aging and sex can explain this difference. Thus, innate immune memory or trained immunity mediated by epigenetic mechanisms is also involved in the variability response against COVID-19. The action of an adaptative immune response, in particular, antigen presentation via HLA is also a key element in this variability. Finally, each viral strain's capacity in evading the action of the immune response has also been suggested as an important mechanism by which certain patients infected with SARS-CoV-2 develop severity and others did not develop any clinical symptoms.
\end{abstract}

Keywords: COVID-19; immune response; PRRs; HLA; epigenetic; trained immunity.

(C) 2020 by the authors. This article is an open-access article distributed under the terms and conditions of the Creative Commons Attribution (CC BY) license (https://creativecommons.org/licenses/by/4.0/).

\section{Introduction}

In December 2019, a new viral infection attracted extensive attention from the worldwide community. This pathogenic virus is a novel $\beta$-coronavirus called Severe Acute Respiratory Syndrome Coronavirus 2 (SARS-CoV-2) [1]. In February, this chronic infection was declared the World Health Organization (WHO) as a pandemic that caused about five million confirmed cases with a mortality rate of about 300.000-500.000 cases [2].

Why the immune system does not effectively attack SARS-CoV-2 remains a largely unknown issue. However, certain elements are in favor of several hypotheses. Indeed, cells of the immune system are among the major preferential targets (tropism) of SARS-CoV-2, which implies dysfunction of the cellular and humoral pathway and the persistence of prolonged inflammation [3]. Also, the pathophysiology of COVID-19 on other organs, notably the 
respiratory system, creates a state of hypoxia and indirectly affects the functioning of the immune system via less energetic metabolic reprogramming $[4,5]$.

The immune response against SARS-CoV-2 remains largely unknown. However, recent investigations show that the immune pathways directed against viral antigens are multiple. In fact, the virus's antigens are recognized by receptors of the innate immune system called pattern recognition receptors (PRR) at the intracellular level. Almost coronavirus is recognized by PRRs such as Toll-like receptors (TLRs) and RIG-I-like receptors (RLRs), recognizing the viral RNA. Other PRRs like endosomal TLR7 and TLR8 recognize the viral ssRNA [6]. This recognition stimulates the secretion of different pro-inflammatory factors via the activation of the transcription factor NF-kB pathways [7]. In this step, there is important variability in PRRs between humans. This variability can be genetically established through polymorphism and/or via the differential expression of these receptors through epigenetic dysregulation. On the other hand, the adaptative immune system's intervention involves antigens' presentation through human leukocyte antigen (HLA). Several studies have shown that the variability in HLA between individual predisposes to different adaptative responses.

Immune evading is another mechanism by which some viruses, and probably SARSCoV-2 escape the immune system's action. Indeed, it has been shown that the M protein of coronavirus suppresses interferon production in a virus-specific manner [8]. It seems that inhibition is also mediated by SARS-CoV-2 and therefore inhibit immune system action. Therefore, the evading action depends on the individual and can be considered a criterium by which there are important differences between patients infected by SARS-CoV-2.

\section{Immunopathological Events Mediated by SARS-CoV-2}

The pathogenesis of COVID-19 caused by SARS-CoV-2 is related to its high contagiousness and its high ability to infect the lower airways resembling SARS-CoV and MERS-CoV cause fatal pneumonia $[9,10]$. The immunopathological effects of SARS-CoV-2 in several hospitalized cases represent one of the important factors leading to health complications and may be the cause of death [3]. Generally, the immune response plays a key tool in fighting SARS-CoV-2 either in asymptomatic patients or in mild symptomatic ones. Once SARS-CoV-2 affects the body, it could be recognized firstly by alveolar macrophages. A primary cytokine storm triggering by pro-inflammatory cytokines and chemokines produced mainly by alveolar macrophages, epithelial cells, and endothelial cells is important to attract virus-specific $T$ cells to the site of infection. The immune cells could eliminate the infected cells effectively and prevent the spread of the virus. This local immune intervention leads to clearance of the virus with minimal lung damage in most patients [3].

However, this process is not the case in severely symptomatic patients where disorder immune response could represent a source of health damage, which increases the fatality rate in severely ill patients [11]. In this regard, and the absence of specific vaccines recommended for COVID-19 infection, understanding the impact of the dysfunctional immune response on health complication in the case of SARS-CoV-2 is very important for appropriate therapeutic intervention. Suppose the local immune response fails to resolve the infection. In that case, SARS- CoV-2 will continue to infect more lung cells and destroy them. In addition to the virus's damage, the cytokine storm caused by the uncontrolled release of pro-inflammatory cytokines and the massive inflammatory cell infiltration leads to a systemic inflammation that developed in acute lung injury acute respiratory distress syndrome (ARDS). The rate fluctuation of 
various immune cell types, as well as cytokines in COVID-19 severe patients, is characterized by lymphopenia, where total $\mathrm{T}$ cell number, CD4+ T helper cells and CD8+ cytotoxic T cells, B cells, and NK cells were significantly decreased [12,11]. However, neutrophils, IL-2, proinflammatory cytokines IL-6, IL-10, IFN- $\alpha$, IFN- $\gamma$, and TNF- $\alpha$ were significantly increased compared to mild symptomatic patients $[13,12]$. The cytokine storm due to uncontrolled systemic inflammatory response is considered one of the main factors causing ARDS in COVID-19 patients. Furthermore, the pro-inflammatory cytokines invade all over the body through circulation resulting in multiple organ failure in severely ill patients, especially of the cardiac, renal, and hepatic systems [14], as they might cause thrombocytopenia [15].

Moreover, the antibody-dependent enhancement (ADE) phenomenon might represent another source of the immunopathological issue in the case of SARS-CoV-2, where antibodies could correlate with disease severity in patients instead of being a means of protection. This phenomenon was observed in various viral infections like SARS-CoV, in which virus diluted antibodies mediated ADE against envelope spike proteins [16]. The study of ADE phenomenon in SARS-CoV-2 is important within the context of the development of safe vaccines knowing that SARS-CoV-2 and SARS-CoV share 79.6\% sequence identity, both use (ACE2) as entry receptor, and cause severe acute respiratory syndromes. In addition, SARS-CoV-2 infection is characterized by detecting high levels of total antibodies, notably IgG and IgM, in severe patients [17].

The adoption of immunomodulatory treatment in combination with antiviral drugs in the Treatment Protocol of COVID-19 is indispensable to reduce the cytokine storm in severely ill patients. Chloroquine and hydroxychloroquine, known for their anti-inflammatory and immunomodulatory effects in the case of rheumatic diseases, are used efficiently to treat COVID-19. In fact, chloroquine and hydroxychloroquine could reduce the production of a range of pro-inflammatory cytokines involved in the cytokine storm, such as IL-1, IL-6, IFN$\alpha$, and TNF- $\alpha$ [18]. In addition to their immunomodulatory effect, these molecules are also characterized by their antiviral activity that interrupts the viral cycle [19], [20]. Hydroxychloroquine used to treat malaria and autoimmune diseases showed great results in reducing and disappearing viral load in COVID-19 when associated with azithromycin [21]. In addition, Tocilizumab is a recombinant humanized anti-human IL-6 receptor monoclonal antibody, which is used efficiently in treating COVID-19 patients due to its high affinity to bind to the IL-6 receptor, which allows alleviating the cytokine storm and severe inflammatory responses in lungs and other organs [22, 23]. On the other hand, the use of glucocorticoids as an immunomodulator in the treatment of coronavirus 2 pneumonia does not reach a consensus [24, 14]. Zhou et al. [25] reported, according to their clinical experience, that the implication of corticosteroids treatment in a lower dose and short duration only for COVID-19 severe patients should alleviate the anti-inflammatory response, which could help to gain time for treating infection and preventing multiple organ failure.

\section{Innate Immune Responses to SARS-CoV-2}

Through evolution, human cells have developed several receptors called pattern recognition receptors (PRRs) to identify pathogen-associated molecular patterns (PAMPs) and damage-associated (endogenous molecules) molecular patterns (DAMPs). These PRRs include numerous receptors, which the most well-known are cytoplasmic Toll-like receptors (TLRs), retinoic acid-inducible gene-I receptor (RIG-I), RIG-I-like receptor (RLR), nucleotide-binding 
oligomerization domain-like receptor (NLR) [26]. It has been shown that TLRs, in particular TLR7, are involved mainly in the recognition of single-stranded RNA viruses, and therefore stimulate interferons (IFNs) type I and III and pro-inflammatory cytokines, which regulate the production of these INFs [27]. Indeed, INFs can act at the first step and limit viral entry and/or viral replication [28]. Moreover, IFNs can also inhibit viral assembly at the early step of the viral cycle. On the other hand, released cytokines can also stimulate the immune system by promoting its major cells such as macrophage, B cell, NK, and T [29].

Until now, the innate responses of the human immune system to SARS-CoV-2 is not well understood. however, based on the data from the ancient coronaviruses, SARS-CoV and MERS-CoV, the immune response mechanism can be predicted due to their high similarity. The recent data show that COVID-19 patients exhibited an elevated expression of proinflammatory genes, especially chemokines, compared with controls. These patients also showed overactivation of IFN-inducible genes (ISGs), which cause immunopathologic effects as a result of due to high inflammation [25]. Also, a decrease in innate immune cells, especially activated dendritic cells and neutrophils [25].

\subsection{Viral recognition by PRRs.}

The innate response constitutes the first line of defense of the human body after the viral infection. The innate responses are mediated by the recognition of viral particles, known as pathogen-associated molecular patterns (PAMPs), by their receptors called pattern recognition receptors (PRRs) [30-31]. The most important PRRs in viral infection are Toll-like receptors (TLRs) and RIG-I-like receptors (RLRs), which recognize the viral RNA [6]. Upon the viral infection, the endosomal TLR7 and TLR8 recognize the viral ssRNA. This recognition leads to the activation of the adapter protein MyD88, which activates the transcription factor NF-kB. NF-kB stimulates pro-inflammatory cytokine production, such as IL-6 and TNF- $\alpha$ [6]. On the other hand, the cytosolic RIG-I/MDA-5 recognizes the viral dsRNA, which provokes the adapter protein MAVS recruitment. MAVS stimulates the transcription factors IRF3 and IRF7, and ultimately initiates the production of type I interferons such as IFN- $\alpha$ and IFN- $\beta$ [7]. The viral protein, such as protein $\mathrm{E}$ and protein $3 \mathrm{a}$, can activate the inflammasome sensor NLRP3. The activation of inflammasome results in the secretion of IL-1 $\beta$ (a highly inflammatory cytokine) and pyroptosis induction (an inflammatory form of cell death).

\subsection{Type I interferon response.}

Type I interferon response is essential during the early phase of the infection. Its role is to limit the virus propagation, efficiently and rapidly, into the host cells. Type I interferons block the viral replication directly and modulate the innate and adaptative immune responses [32]. Type I interferon receptors are expressed on the surface of several immune cells, including macrophages. The binding of type I IFNs to their receptors induces the activation of JAK/STAT signaling pathway. This pathway leads to the formation of STAT1/STAT2/IRF9 complex (a transcriptional factor) that induces the IFN-stimulated genes (ISGs), such as RNAse L (antiviral enzyme) and pro-inflammatory chemokine such as CXCL10 [32].

The timing of IFN-I production was reported to determine the infection development in the mouse. In MERS-CoV, Channappanavar et al. [33] showed that the early production of type I IFN protects the patient. However, delayed production of IFN-I leads to an inability to 
control the viral replication. This loss of control leads to increasing viral loads and host cell damage as well as a cytokine storm, which aggravates the disease.

Mitochondria play a capital role in human life cells. It assures adenosine triphosphate production (ATP) via the electron transport chain generated by the oxidation of tricarboxylic acid and the beta-oxidation of fatty acids. It has been shown that mitochondrial phosphorylation activity decreases with aging. Therefore, the energy level decreases, which induces a reduction in immune system functions [34].

Moreover, during molecular oxygen reduction reaction, mitochondria can generate reactive oxygen species (ROS) [35], and an excessive rate of these ROS causes several damages [36]. Therefore, an increase in ROS production is known as an important criterium of aging. Moreover, the human body's natural antioxidant capacity decreases with aging by reducing natural detoxifying enzymes such as catalase, superoxide dismutase, glutathione peroxidase, and glutathione reductase [37]. It has been shown that mitochondria regulate innate and adaptive immunity via the stimulation of NF- $\mathrm{B}, \mathrm{NLRP} 3$ pathways, interferon-regulatory factors, and mediate cytotoxic responses [34], [38]. The decrease of ATP, the increase of ROS, and the reduction of natural antioxidant capacity seem to be efficient in dysregulating the immune system capacity and, therefore, increasing the inflammatory response and the severity of COVID-19.

\section{Adaptive Immune Response to SARS-CoV-2: HLA Variability Involved in SARS-CoV-2 Antigen Presentation}

The adaptive immunity to SARS-CoV-2 includes humoral and cellular components. Humoral immunity is mediated principally by antibodies released from B lymphocytes, while T lymphocytes mediate cellular immunity.

\subsection{Humoral immunity to SARS-CoV-2 infection.}

Humoral immunity, mediated principally by antibodies released from B lymphocytes, plays a key role in protecting against future virus infection by producing neutralizing antibodies [39]. In fact, infection with SARS-CoV-2 induces the production of IgG antibodies against protein $\mathrm{N}$, which can be detected in the serum of patients after 4 days of infection [40]. In addition to the antibodies, the humoral immune response also includes supplements such as C3a and C5a [41].

Clinical data on the role of complement activation in the development of acute respiratory distress syndrome (ARDS) associated with SARS-CoV-2 are scarce. Indeed, a recent study on SARS-CoV, which is closely linked to SARS-CoV-2, revealed that activation of the complement component $\mathrm{C} 3$ exacerbates the disease in SARS-CoV-2 associated with ARDS [42]. This study in mice suggested that inhibition of C3 might alleviate the pulmonary inflammatory complications of SARS-CoV-2 infection. In addition, C3 inhibition could simultaneously block the generation of $\mathrm{C} 3 \mathrm{a}$ and $\mathrm{C} 5 \mathrm{a}$, as well as intrapulmonary activation of C3 and release of IL-6 from alveolar macrophages or other cells that express C3a receptors (C3aRs) and/or C5a receptors (C5aRs), thereby improving lung injury [43]. 


\subsection{Cellular immunity to SARS-CoV-2 infection.}

Besides humoral immunity, the adaptive immune response joins the fight against the virus. T cells' specific responses in the adaptive immune system (including CD4 + and CD8 + $\mathrm{T}$ cells) against SARS-CoV-2 play an essential role in the recognition and destruction of infected cells [44]. T helper cells coordinate the overall adaptive response, while cytotoxic $\mathrm{T}$ cells are essential for killing infected viral cells. In general, CD4 + T cells stimulate B cells to produce antibodies specific to the virus, and CD8 + T cells directly kill infected cells [45]. As soon as SARS-CoV-2 enters respiratory epithelial cells, viral peptides are presented via class I major histocompatibility complex (MHC) proteins to CD8 + cytotoxic T lymphocytes. These cells activate, divide, and cause lysis of tissue cells infected by the virus. In addition, these cytotoxic CD8 + T cells begin to develop effector and memory T cells specific to SARS-CoV2. Subsequently, the virus and its viral particles will be recognized via professional cells to present antigens (dendritic cells and macrophages), which present the viral peptides to CD4 + T cells via the MHC class II complex [46].

The predominance between these two types of T lymphocytes in SARS-CoV has been reported in several studies showing that $\mathrm{CD} 4+\mathrm{T}$ cell responses were less frequent with a lower amplitude than CD8 + T cells. In addition, unlike $\mathrm{T}$ lymphocytes from mild-moderate group viruses, those from severe group viruses tended to be a central memory phenotype with a higher frequency of polyfunctional CD4 + T lymphocytes (IFN $\gamma, \mathrm{TNF} \alpha$, and IL-2) and CD8 + T lymphocytes (IFN $\gamma, \mathrm{TNF} \alpha$, and degranulated state) [44].

\subsection{HLA variability involved in SARS-CoV-2 antigen presentation.}

In several viral pathologies, including SARS-CoV-2, mutations in the HLA genes influence the immune system's response and influence the severity of the disease. In fact, the HLA genes are the most polymorphic in humans (there are many alleles for each of them). They are codominant (they are expressed in the phenotype as soon as they are present in the genotype). The classic HLA loci are class I (HLA-A, B, C, E, F, and G) and class II (HLA-DR, DQ, DM, and DP) molecules, which provide an antigen presentation to CD4 and CD8 T-cells [47].

HLA molecules' primary role is to present peptides derived from pathogens to T cells, thereby enabling an adaptive immune cell response. Generally, the HLA class I and II genes encode protein receptors that orchestrate the immune response by presenting foreign or modified auto-antigens to T lymphocytes. However, genetic variations influence the ability of the immune system to recognize a given pathogen.

During SARS-CoV-2 infection, the genetic variability between the three genes of the major histocompatibility complex (MHC) class I (human leukocyte antigen (HLA) A, B and C) can affect the sensitivity and severity of illness. These individual genetic variations may explain the difference in immune responses between patients with COVID-19 disease, some with stronger responses than others may. Indeed, a weak recognition of the virus could lead a patient to be more vulnerable to it.

Based on an in silico analysis, a recent study evaluated the binding affinity between the immunogenic peptides derived from the SARS-CoV-2 virus and HLA class I molecules, encoded by 145 HLA -A, -B, and -VS. The results showed that the HLA-B * 15: 03 allele had the greatest capacity to present highly conserved peptides predicted for SARS-CoV-2, which 
are shared between human coronaviruses, suggesting that it could allow $\mathrm{T}$ cell-based crossimmunity. However, the HLA-B * 46: 01 allele had the least number of binding peptides predicted for SARS-CoV-2, suggesting that individuals with this allele might be particularly vulnerable to COVID- 19 [48]. This allele's presence had already been associated with severe forms of SARS-CoV, the coronavirus strain responsible for Severe Acute Respiratory Syndrome (SARS) [49].

Another study was carried out in order to define immunodominant epitopes from SARS-CoV-2 proteins. 25 epitopes were mapped containing 9 to 28 amino acid residues; the length of most epitopes was 16 to 18 residues. The results obtained from the structural and molecular docking analysis showed that the epitopes 9 to 11 residues in length were mainly recognized by the HLA MHC class I proteins. However, the longer epitopes tended to bind to the MHC class II proteins with higher affinities. Thus, a more in-depth analysis of the treatment of MHC class I revealed that the epitopes of longer sequences can undergo proteasomal treatment and that the central part of the region for the recognition of MHC class I within the epitope can be presented to the cell surface for monitoring by CD8 T cells [50]. This identification of epitopes could be of great importance in the development of an effective SARS-CoV-2 vaccine.

In summary, the genetic differences of these alleles could play on two planes: their propensity to be infected by SARS-CoV-2 and, on the other hand, on the severity of the disease. According to published data, approximately $80 \%$ of those infected have mild symptoms [48]. Understanding how variations in the HLA system could interfere with the development of COVID-19 would help identify people at higher risk for the disease.

\section{Immune Evasion Mechanisms}

Several viruses, including coronaviruses, are known for their capacity to develop different strategies to evade host immune responses. Many strategies for SARS-CoV-2 can be predicted based on the previous coronaviruses, SARS-CoV, and MERS-CoV. In COVID-19 patients, high SARS-CoV-2 loads were observed very early after the symptoms' apparition [51]. This increase in virus loads suggests that the virus can evade the innate host immune system, especially interferon responses.

\subsection{Avoidance.}

The virus evades itself or its by-products from host immune system recognition. It was reported that SARS-CoV and MERS-CoV cover their viral products into a double membrane vesicle during the replication phase [52], [53], [54]. This strategy allows the virus to replicate into the host cell without immune recognition by PRRs.

\subsection{Suppression of IFN induction/Suppression of IFN signaling.}

Studies on SARS-CoV show that some viral structural and non-structural proteins antagonize IFN responses. This antagonism takes place at different stages of IFN signaling pathway. The most important mechanisms include prevention of viral RNA recognition by PRRs [55], inhibition of PRR signaling through TBK1 (inhibitor of NF-kB), TRAF3, and IRF3 [56], suppression of IFN signaling through STAT1, as well as the promotion of host mRNA degradation and host protein translation. Due to the high similarity of SARS-CoV-2 and SARS- 
$\mathrm{CoV}$, there is a high probability that some of these mechanisms are the some in SARS-CoV-2. In addition, the $M$ protein of SARS coronavirus suppresses IFN production in a virus-specific manner, which targets TRAF3. It prevents it from interacting with TANK, TBK1, and IKKe $[8]$.

\subsection{Epigenetic modulation.}

It has been suggested that SARS-CoV-2 viral miRNAs target several immune signaling pathways such as IFN-1, autophagy, and apoptosis and can therefore escape from immune response mechanisms and prolong their latency cycle inside some hosts without any symptoms of COVID-19 [57].

\section{Involvement of Epigenetic Variability Regulation in Immune System Anti-SARS-CoV-2 Response}

Genetic changes without physical modification of genetic material are currently explained by epigenetic processes. Epigenetic changes include DNA methylation, histone changes, and chromatin remodeling, among others. All of these modifications have the ability to express the expression of a gene [58] highly. It has been shown that epigenetic regulation is involved mainly in immune system functioning. Indeed, the expression of different innate and adaptative immune system receptors is under epigenetic control [59]. Specific epigenetic modifications like DNA methylation and chromatin accessibility through histone acetylation/methylation are important in response to viral infection. In fact, patients with infectious diseases epi-genetically respond to pathogens differently. This is mainly explained by the different expressions of innate receptors but also of antibodies directed against viruses. In addition, negative regulation would occur if the pathogen succeeds in thwarting these epigenetic mechanisms [60].

It has been suggested that epigenomic patterns in the immune system are in decrease with age, and therefore make a variability in the severity of infectious diseases. With COVID19, the morbidity and mortality rate were importantly explained by this suggestion [26]. Moreover, the difference between men and women was also attributed to epigenetic variability. Indeed, COVID-19 alterations are more significant in men than in women. This remark was explained by the presence of higher loci-specific methylation decline in the B cells [61].

It has also been suggested that epigenetic modifications in CpG-islands, particularly in sub-telomeric regions that regulate innate immunity, can mediate inflammatory responses to COVID-19 and explain variability responses between individuals infected by SARS-CoV-2. Indeed, it was demonstrated that chronic viral infections accelerate aging by their pression on epigenetic fluctuations as measured by the epigenetic clock [62]. This suggestion is observed in patients with COVID-19, which aging increases, importantly, the rate of mortality and morbidity [26]. Remarkably, it seems that epigenetic clocks can be used as an important criterium to predict the severity of COVID-19 and subsequent exacerbation of chronic diseases in COVID-19 survivors [62,63].

Khan and collaborators investigated the effects of both host and SARS-CoV-2 miRNAs on balancing the pathogenicity and immune response. Indeed, the results showed that the cellular host miRNAs could induce inhibitor effects on virus mechanics epigenetically. Interestingly, the virus also encodes miRNAs and induces epigenetic regulation of cellular host genes transcription [57]. Moreover, the same study revealed that SARS-CoV-2 modulates other 
cellular signaling pathways via epigenetic modulator, leading to increased anomalies in patients with comorbidities, such as those who have diabetes and cardiovascular complications. This might suggest that miRNAs can be a key epigenetic modulator behind the overcomplications amongst the COVID-19 patients [57].

Another important mechanism that differentiates between patients is innate immune memory or trained immunity. Indeed, it has been shown that some cells and molecules of the immune system such as natural killer (NK) cells, innate lymphoid cells, cytokines, and pattern recognition proteins, can keep the memory against pathogens that have infected these host cells in a previous period $[64,65]$. Interestingly, this second innate immune response under innate cell memory becomes stronger and non-specific (against several pathogens) due to transcriptional epigenetic reprogramming $[64,66]$.

Recently, it has been shown that Bacille Calmette-Guerin (BCG) vaccine used against tuberculosis can protect from SARS-CoV-2. Indeed, the decrease of morbidity and mortality in BCG vaccinated individuals was $[67,65]$. It has been shown that BCG vaccinated individuals protected from other pathogenic infections through the rapid expansion of NK cells and their activation to produce cytokines providing T-cell independent protection [68].

\section{Conclusion}

The COVID-19 epidemic continues to cause real health, economic, psychological, and social damage to humanity. The mechanistic understanding of the pathophysiology of this disease is still unknown. This understanding is still difficult to decipher since some people infected with SARS-CoV-2 develop clinical signs or even serious complications that can lead to death. In contrast, some others do not develop clinical signs. This variability is certainly, as we demonstrated in this review, largely dependent on the relationship between the immune system and COVID-19 infection. Several elements of response are addressed to explain this difference between individuals developing an infection or not: variability in PRRs, variability in the HLA system, variability in innate immune memory, and variability in the epigenome of individuals. The virus can also trigger escape mechanisms by inhibiting certain pathways of the innate and adaptive immune system. It can also cause epigenetic deregulation, essentially affecting the expression of surface receptors. The virus enters the cytoplasm of host cells.

\section{Funding}

This research received no external funding.

\section{Acknowledgments}

This research has no acknowledgment.

\section{Conflicts of Interest}

The authors declare no conflict of interest.

\section{References}

1. Singhal, T. A review of coronavirus disease-2019 (COVID-19). The Indian Journal of Pediatrics 2020, 87, 1-6, https://doi.org/10.1007/s12098-020-03263-6.

2. Park, M.; Cook, A.R.; Lim, J.T.; Sun, Y.; Dickens, B.L. A systematic review of COVID-19 epidemiology based on current evidence. Journal of Clinical Medicine 2020, 9, https://doi.org/10.3390/jcm9040967. 
3. Tay, M.Z.; Poh, C.M.; Rénia, L.; MacAry, P.A.; Ng, L.F. The trinity of COVID-19: immunity, inflammation and intervention. Nature Reviews Immunology 2020, 20, 1-12, https://doi.org/10.1038/s41577-020-0311-8.

4. Shi, Y.; Wang, Y.; Shao C.; Huang, J.; Gan, J.; Huang, X.; Bucci, E.; Piacentin,i M.; Ippolito, G.; Melino, G. COVID-19 infection: the perspectives on immune responses. Cell Death Differ. 2020, 27, 1451-1454, https://doi.org/10.1038/s41418-020-0530-3.

5. Li, X.; Geng, M.; Peng, Y.; Meng, L.; Lu, S. Molecular immune pathogenesis and diagnosis of COVID-19. Journal of Pharmaceutical Analysis 2020, 10, 102-108, https://doi.org/10.1016/j.jpha.2020.03.001.

6. Jensen, S.; Thomsen, A.R. Sensing of RNA viruses: a review of innate immune receptors involved in recognizing RNA virus invasion. Journal of virology 2012, 86, 2900-2910, https://doi.org/10.1128/JVI.05738-11.

7. Totura, A.L.; Baric, R.S. SARS coronavirus pathogenesis: host innate immune responses and viral antagonism of interferon. Current opinion in virology 2012, 2, 264-275, https://doi.org/10.1016/j.coviro.2012.04.004.

8. Siu, K.L.; Yung, M.L.; Kok, K.H.; Yuen, K.S.; Kew, C.; Lui, P.Y.; Chan, C.P.; Tse, H.; Woo, P.C.W.; Yuen, K.Y.; Jin, D.Y. Middle east respiratory syndrome coronavirus 4a protein is a double-stranded RNA-binding protein that suppresses PACT-induced activation of RIG-I and MDA5 in the innate antiviral response. Journal of virology 2014, 88, 4866-4876, https://doi.org/10.1128/JVI.03649-13.

9. Channappanavar, R.; Perlman, S. Pathogenic human coronavirus infections: causes and consequences of cytokine storm and immunopathology. Seminars in immunopathology 2017, 5, 529-539, https://doi.org/10.1007/s00281-017-0629-x.

10. Zhou, W.; Liu, Y.; Tian, D.; Wang, C.; Wang, S.; Cheng, J.; Hu, M.; Fang, M.; Gao, Y. Potential benefits of precise corticosteroids therapy for severe 2019-nCoV pneumonia. Signal transduction and targeted therapy 2020a, 5, 1-3, https://doi.org/10.1038/s41392-020-0127-9.

11. Xu, Z.; Shi, L.; Wang, Y.; Zhang, J.; Huang, L.; Zhang, C.; Liu, S.; Zhao, P.; Liu, H.; Zhu, L.; Tai, Y.; Bai, C.; Gao, T.; Song, J.; Xia, P.; Dong, J.; Zhao, J.; Wang, F.S.; Tai, Y. Pathological findings of COVID-19 associated with acute respiratory distress syndrome. The Lancet respiratory medicine 2020a, 8, 420-422, https://doi.org/10.1016/S2213-2600(20)30076-X.

12. Tan, M.; Liu, Y.; Zhou, R.; Deng, X.; Li, F.; Liang, K.; Shi, Y. Immunopathological characteristics of coronavirus disease 2019 cases in Guangzhou, China. Immunology 2020, https://doi.org/10.1111/imm.13223.

13. Huang, C.; Wang, Y.; Li, X.; Ren, L.; Zhao, J.; Hu, Y.; Zhan, L.; Fan, G.; Xu, J.; Gu, X.; Cheng, Z.; Yu, T.; Xia, J.; Wei, Y.; Wu, W.; Xie, X.; Yin, W.; Li, H.; Cao, B. Clinical features of patients infected with 2019 novel coronavirus in Wuhan, China. The lancet 2020, 39, 497-506, https://doi.org/10.1016/S01406736(20)30183-5.

14. Zhang, W.; Zhao, Y.; Zhang, F.; Wang, Q.; Li, T.; Liu, Z.; Wang, J.; Qin, Y.; Zhang, X.; Yan, X.; Zeng, X.; Zhang, S. The use of anti-inflammatory drugs in the treatment of people with severe coronavirus disease 2019 (COVID-19): The experience of clinical immunologists from China. Clinical Immunology 2020b, 214, https://doi.org/10.1016/j.clim.2020.108393.

15. Xu, P.; Zhou, Q.; Xu, J. Mechanism of thrombocytopenia in COVID-19 patients. Annals of Hematology 2020b, 99, 1205-1208, https://doi.org/10.1007/s00277-020-04019-0.

16. Wang, S.F.; Tseng, S.P.; Yen, C.H.; Yang, J.Y.; Tsao, C.H.; Shen, C.W.; Chen, K.H.; Liu, F.T.; Liu, W.T.; Chen, Y.M.A.; Huang, J.C. Antibody-dependent SARS coronavirus infection is mediated by antibodies against spike proteins. Biochemical and biophysical research communications 2014, 451, 208-214, https://doi.org/10.1016/j.bbrc.2014.07.090.

17. Iwasaki, A.; Yang, Y. The potential danger of suboptimal antibody responses in COVID-19. Nature Reviews Immunology 2020, 20, 1-3, https://doi.org/10.1038/s41577-020-0321-6.

18. Schrezenmeier, E.; Dörner, T. Mechanisms of action of hydroxychloroquine and chloroquine: implications for rheumatology. Nature Reviews Rheumatology 2020, 16, 1-12, https://doi.org/10.1038/s41584-020-0372$\mathrm{x}$.

19. Wang, L.F.; Lin, Y.S.; Huang, N.C.; Yu, C.Y.; Tsai, W.L.; Chen, J.J.; Kubota, T.; Matsuoka, M.; Chen, S.R.; Yang, C.S.; Lu, R.W.; Lin, Y.L.; Chang, T.H. Hydroxychloroquine-inhibited dengue virus is associated with host defense machinery. Journal of Interferon \& Cytokine Research 2015, 35, 143-156, https://doi.org/10.1089/jir.2014.0038.

20. Randolph, V.B.; Winkler, G.; Stollar, V. Acidotropic amines inhibit proteolytic processing of flavivirus prM protein. Virology 1990, 174, 450-458, https://doi.org/10.1016/0042-6822(90)90099-D.

21. Gautret, P.; Lagier, J.C.; Parola, P.; Hoang, V.T.; Meddeb, L.; Mailhe, M.; Doudier, B.; Courjon, J.; Giordanengo, V.; Vieira, V.E.; Dupont, H.T.; Honoré, S.; Colson, P.; Chabrière, E.; La Scola, B.; Rolain, J.M.; Brouqui, P.; Raoult, R. Hydroxychloroquine and azithromycin as a treatment of COVID-19: results of an open-label non-randomized clinical trial. International journal of antimicrobial agents 2020, 56, https://doi.org/10.1016/j.ijantimicag.2020.105949.

22. Xu, X. Han, M.; Li, T.; Sun, W.; Wang, D.; Fu, B.; Zhou, Y.; Zheng, X.; Yang, Y.; Li, X.; Zhang, X.; Pan, A.; Wei, H. Effective treatment of severe COVID-19 patients with tocilizumab. Proceedings of the National Academy of Sciences 2020c, 117, 10970-10975, https://doi.org/10.1073/pnas.2005615117. 
23. Zhang, C.; Wu, Z.; Li, J.W.; Zhao, H.; Wang, G.Q. The cytokine release syndrome (CRS) of severe COVID19 and Interleukin-6 receptor (IL-6R) antagonist Tocilizumab may be the key to reduce the mortality. International journal of antimicrobial agents 2020a, 55, https://doi.org/10.1016/j.ijantimicag.2020.105954.

24. Russell, C.D.; Millar, J.E.; Baillie, J.K. Clinical evidence does not support corticosteroid treatment for 2019nCoV lung injury. The Lancet 2020, 395, 473-475, https://doi.org/10.1016/S0140-6736(20)30317-2.

25. Zhou, Z.; Ren, L.; Zhang, L.; Zhong, J.; Xiao, Y.; Jia, Z.; Guo, L.; Yang, J.; Wang, C.; Jiang, S.; Yang, D.; Zhang, G.; Li, H.; Chen, F.; Xu, Y.; Chen, M.; Gao, Z.; Yang, J.; Wang, J. Heightened innate immune responses in the respiratory tract of COVID-19 patients. Cell Host \& Microbe 2020b, 27, 883-890.e2, https://doi.org/10.1016/j.chom.2020.04.017.

26. Salimi, S. and Hamlyn, J.M. COVID-19 and Crosstalk with the Hallmarks of Aging. Preprints 2020, https://doi.org/10.20944/preprints202004.0182.v2.

27. Akira, S.; Uematsu, S.; Takeuchi, O. Pathogen recognition and innate immunity. Cell 2006, 124, 783-801, https://doi.org/10.1016/j.cell.2006.02.015.

28. Dittmann, M.; Hoffmann, H.-H.; Scull, M.A.; Gilmore, R.H.; Bell, K.L.; Ciancanelli, M.; Wilson, S.J.; Crotta, S.; Yu, Y.; Flatley, B.; Xiao, Jing W.; Casanova, J.-L.; Wack, A.; Bieniasz, P.D.; Rice, C.M.A. A serpin shapes the extracellular environment to prevent influenza A virus maturation. Cell 2015, 160, 631643, https://doi.org/10.1016/j.cell.2015.01.040.

29. Kawai, T.; Akira, S. The role of pattern-recognition receptors in innate immunity: Update on Toll-like receptors. Nat. Immunol. 2010, 11, 373-384, https://doi.org/10.1038/ni.1863.

30. Saito, T.; Gale, Jr.M. Principles of intracellular viral recognition. Current opinion in immunology 2007, 19, 17-23, https://doi.org/10.1016/j.coi.2006.11.003.

31. Haller, O.; Kochs, G.; Weber, F. The interferon response circuit: induction and suppression by pathogenic viruses. Virology 2006, 344, 119-130, https://doi.org/10.1016/j.virol.2005.09.024.

32. Channappanavar, R.; Fehr, A.R.; Zheng, J.; Wohlford-Lenane, C.; Abrahante, J.E.; Mack, M.; Sompallae, R.; McCray, P.B., Jr.; Meyerholz, D.K.; Perlman, S. IFN-I response timing relative to virus replication determines MERS coronavirus infection outcomes. The Journal of Clinical Investigation 2019, 129, 36253639, https://doi.org/10.1172/JCI126363.

33. Mills, E.L.; Kelly, B.; O'Neill, L.A.J. Mitochondria are the powerhouses of immunity. Nat. Immunol. 2017, 18488-498, https://doi.org/10.1038/ni.3704.

34. Breda, C.N.S.; Davanzo, G.G.; Basso, P.J.; Saraiva, Camar, N.O.; Moraes-Vieira, P.M.M. Mitochondria as central hub of the immune system. Redox Biol. 2019, 26, https://doi.org/10.1016/j.redox.2019.101255.

35. Fung, T.S.; Liu, D.X. Human coronavirus: Host-pathogen interaction. Annu. Rev. Microbiol. 2019, 73, 529557, https://doi.org/10.1146/annurev-micro-020518-115759.

36. Espinoza, S.E.; Guo, H.; Fedarko, N.; DeZern, A.; Fried, L.P.; Xue, Q.-L.; Leng, S.; Beamer, B.; Walston, J.D. Glutathione Peroxidase Enzyme Activity in Aging. The Journals of Gerontology: Series A 2008, 63, 505-509, https://doi.org/10.1093/gerona/63.5.505.

37. Schumacker, P.T.; Gillespie, M.N.; Nakahira, K.; Choi, A.M.K.; Crouser, E.D.; Piantadosi, C.A.; Bhattacharya, J. Mitochondria in lung biology and pathology: more than just a powerhouse. American Journal of Physiology-Lung Cellular and Molecular Physiology 2014, 306, L962-L974, https://doi.org/10.1152/ajplung.00073.2014.

38. Gorse, G.J.; Donovan, M.M.; Patel, G.B. Antibodies to coronaviruses are higher in older compared with younger adults and binding antibodies are more sensitive than neutralizing antibodies in identifying coronavirus-associated illnesses. J. Med. Virol. 2020, 92, 512-517, https://doi.org/10.1002/jmv.25715.

39. Hsueh, P.R.; Huang, L.M.; Chen, P.J.; Kao, C.L.; Yang, P.C. Chronological evolution of IgM, IgA, IgG and neutralisation antibodies after infection with SARS-associated coronavirus. Clin. Microbiol. Infect. 2004, 10, 1062-1066, https://doi.org/10.1111/j.1469-0691.2004.01009.x.

40. Mathern, D.R.; Heeger, P.S. Molecules Great and Small: The Complement System. Clin. J. Am Soc. Nephrol. 2015, 10, 1636-50, https://doi.org/10.2215/CJN.06230614.

41. Gralinski, L.E.; Sheahan, T.P.; Morrison, T.E.; Menachery, V.D.; Jensen, K.; Leist, S.R.; Whitmore, A.; Heise, M.T.; Baric, R.S. Complement Activation Contributes to Severe Acute Respiratory Syndrome Coronavirus Pathogenesis. mBio 2018, 9, e01753-18, https://https://doi.org/10.1128/mBio.01753-18.

42. Risitano, A.M.; Mastellos, D.C.; Huber-Lang, M.; Yancopoulou, D.; Garlanda, C.; Ciceri, F.; Lambris, J.D. Complement as a target in COVID-19? Nature Reviews Immunology 2020, 20, 343-344, https://doi.org/10.1038/s41577-020-0320-7.

43. Prompetchara, E.; Ketloy, C.; Palaga, T. Immune responses in COVID-19 and potential vaccines: lessons learned from SARS and MERS epidemic. Asian Pac. J. Allergy Immunol. 2020, 38, 1-9, https://doi.org/10.12932/AP-200220-0772.

44. Rokni, Z.; Ghasemi, V.; Tavakli, Z. Immune responses and pathogenesis of SARS-CoV-2 during an outbreak in Iran: Comparison with SARS and MERS. Med. Virol. 2020, 30, https://https://doi.org/10.1002/rmv.2107.

45. Azkur, A.K.; Akdis, M.; Azkur, D.; Sokolowska, M.; van de Veen, W.; Brüggen, M.-C.; O’Mahony, L.; Gao, Y.; Nadeau, K.; Akdis, C.A. Immune response to SARS-CoV-2 and mechanisms of immunopathological changes in COVID-19. Allergy 2020, 75, 1564-1581, https://doi.org/10.1111/ALL.14364. 
46. Blackwell, J.M.; Jamieson, S.E.; Burgner, D. HLA and infectious diseases. Clin. Microbiol. Rev. 2009, 22, 370-385, https://doi.org/10.1128/CMR.00048-08.

47. Nguyen, A.; David, J.K.; Maden, S.K.; Wood, M.A.; Weeder, B.R.; Nellore, A.; Thompson, R.F. Human leukocyte antigen susceptibility map for SARS-CoV-2. Journal of Virology 2020, https://doi.org/10.1101/2020.03.22.20040600.

48. Lin, M.; Tseng, H.-K.; Trejaut, J.A.; Lee, H.-L.; Loo, J.-H.; Chu, C.-C.; Chen, P.-J.; Su, Y.-W.; Lim, K.H.; Tsai, Z.-U.; Lin, R.-Y.; Lin, R.-S.; Huang, C.-H. Association of HLA class I with severe acute respiratory syndrome coronavirus infection. BMC Med. Genet. 2003, 4, https://doi.org/10.1186/1471-2350-4-9.

49. Mukherjee, S.; Tworowski, D.; Detroja, R.; Mukherjee, S.B.; Frenkel-Morgenstern, M. Immunoinformatics and Structural Analysis for Identification of Immunodominant Epitopes in SARS-CoV-2 as Potential Vaccine Targets. Vaccines 2020, 8, https://doi.org/10.3390/vaccines8020290.

50. Zou, L.; Ruan, F.; Huang, M.; Liang, L.; Huang, H.; Hong, Z.; Yu, J.; Kang, M.; Song, Y.; Xia, J.; Guo, Q.; Song, T.; He, J.; Yen, H.-L.; Peiris, M.; Wu, J. SARS-CoV-2 Viral Load in Upper Respiratory Specimens of Infected Patients. New England Journal of Medicine 2020, 382, 1177-1179, https://doi.org/10.1056/NEJMc2001737.

51. Prentice, E.; Jerome, W.G.; Yoshimori, T.; Mizushima, N.; Denison, M.R. Coronavirus replication complex formation utilizes components of cellular autophagy. Journal of Biological Chemistry 2004, 279, 1013610141, https://doi.org/10.1074/jbc.M306124200.

52. Snijder, E.J.; Van Der Meer, Y.; Zevenhoven-Dobbe, J.; Onderwater, J.J.; van der Meulen, J.; Koerten, H.K.; Mommaas, A.M. Ultrastructure and origin of membrane vesicles associated with the severe acute respiratory syndrome coronavirus replication complex. Journal of virology 2006, 80, 5927-5940, https://doi.org/10.1128/JVI.02501-05.

53. Stertz, S.; Reichelt, M.; Spiegel, M.; Kuri, T.; Martínez-Sobrido, L.; García-Sastre, A.; Weber, F.; Kochs, G. The intracellular sites of early replication and budding of SARS-coronavirus. Virology 2007, 361, 304315, https://doi.org/10.1016/j.virol.2006.11.027.

54. Thiel, V.; Weber, F. Interferon and cytokine responses to SARS-coronavirus infection. Cytokine \& growth factor reviews 2008, 19, 121-132, https://doi.org/10.1016/j.cytogfr.2008.01.001.

55. Spiegel, M.; Pichlmair, A.; Martínez-Sobrido, L.; Cros, J.; García-Sastre, A.; Haller, O.; Weber, F. Inhibition of beta interferon induction by severe acute respiratory syndrome coronavirus suggests a two-step model for activation of interferon regulatory factor 3. Journal of virology 2005, 79, 2079-2086, https://doi.org/10.1128/JVI.79.4.2079-2086.2005.

56. Khan, M.A.A.K.; Sany, M.R.U.; Islam, M.S.; Mehebub, M.S.; Islam, A.B. Epigenetic regulator miRNA pattern differences among SARS-CoV, SARS-CoV-2 and SARS-CoV-2 worldwide isolates delineated the mystery behind the epic pathogenicity and distinct clinical characteristics of pandemic COVID-19. bioRxiv 2020, https://doi.org/10.1101/2020.05.06.081026.

57. Allis, C.D.; Jenuwein, T. The molecular hallmarks of epigenetic control. Nature Reviews Genetics 2016, 17, https://doi.org/10.1038/nrg.2016.59.

58. Issa, J.P. Age-related epigenetic changes and the immune system. Clinical Immunology 2003, 109, 103-108, https://doi.org/10.1016/S1521-6616(03)00203-1.

59. Minarovits, J. Microbe-induced epigenetic alterations in host cells: the coming era of patho-epigenetics of microbial infections: a review. Acta microbiologica et immunologica Hungarica 2009, 56, 1-19, https://doi.org/10.1556/amicr.56.2009.1.1.

60. Márquez, E.J.; Chung, C.-h.; Marches, R.; Rossi, R.J.; Nehar-Belaid, D.; Eroglu, A.; Mellert, D.J.; Kuchel, G.A.; Banchereau, J.; Ucar, D. Sexual-dimorphism in human immune system aging. Nature Communications 2020, 11, https://doi.org/10.1038/s41467-020-14396-9.

61. Boulias, K.; Lieberman, J.; Greer, E.L. An epigenetic clock measures accelerated aging in treated HIV infection. Mol. Cell. 2016, 62, 153-155, https://doi.org/10.1016/j.molcel.2016.04.008.

62. Lu, A.T.; Quach, A.; Wilson, J.G.; Reiner, A.P.; Aviv, A.; Raj, K.; Hou, L.; Baccarelli, A.A.; Li, Y.; Stewart, J.D.; Whitsel, E.A.; Assimes, T.L.; Ferrucci, L.; Horvath, S. DNA methylation GrimAge strongly predicts lifespan and healthspan. Aging 2019, 11, 303-327, https://doi.org/10.18632/aging.101684.

63. Netea, M.G.; Joosten, L.A.B.; Latz, E.; Mills, K.H.G.; Natoli, G.; Stunnenberg, H.G.; O’Neill, L.A.J.; Xavier, R.J. Trained immunity: A program of innate immune memory in health and disease. 2016, 352, https://doi.org/10.1126/science.aaf1098.

64. Covián, C.; Retamal-Díaz, A.; Bueno, S.M.; Kalergis, A.M. Could BCG vaccination induce protective trained immunity for SARS-CoV-2? Frontiers in Immunology 2020, 11, https://doi.org/10.3389/fimmu.2020.00970.

65. Rajarshi, K.; Chatterjee, A.; Ray, S. BCG vaccination strategy implemented to reduce the impact of COVID19: Hype or Hope? Medicine in Drug Discovery 2020, 7, https://doi.org/10.1016/j.medidd.2020.100049.

66. Miller, A.; Reandelar, M.J.; Fasciglione, K.; Roumenova, V.; Li, Y.; Otazu, G.H. Correlation between universal BCG vaccination policy and reduced morbidity and mortality for COVID-19: an epidemiological study. MedRxiv 2020, 1-9, https://doi.org/10.1101/2020.03.24.20042937.

67. Sun, J.C.; Beilke, J.N.; Lanier, L.L. Adaptive immune features of natural killer cells. Nature 2009, 457, 557561, https://doi.org/10.1038/nature07665. 